\title{
The Test of Word Finding (TWF - 2). (A pilot study and validation in Greek pre - school aged children \& data for word retrieval in this population)
}

\author{
Tafiadis Dionysios ${ }^{1,2^{*}}$, Stamatina Larentzaki ${ }^{1}$, Despoina Magioglou ${ }^{1}$, loannis Mpourakis ${ }^{1}$, Maria Neofotistou ${ }^{1}$, \\ Aggeliki Pagoni ${ }^{1}$, Ellisavet Xatiefremidou ${ }^{1}$, Maria Tafiadi ${ }^{3}$
}

From $1^{\text {st }}$ International Congress on Neurobiology and Clinical Psychopharmacology and European Psychiatric Association Conference on Treatment Guidance

Thessaloniki, Greece. 19-22 November 2009

\section{Background}

The present pilot study was the adaption of word finding test [(TWF - 2, 2nd edition (20000 originally created by Diane German in 1985] for Greek children aged from 4 years till 5 years and 11 months, and to locate the ability of word retrieval in pre - school age population.

\section{Materials and methods}

The commercial version of the test was translated in Greek language by a linguist, three speech language therapists and 2 native speakers of Greek language, having proficiency in English, and two native speakers of English having proficiency in Greek, and changes were contacted, for the best representation of the Greek version. In this research took part 200 participants (m: 50, f: 50/per age) recruited from Greek pre - schools settings at the region of Agrinio. The sample was independent from origin and socio - economic situations. Medical examinations' were also requested, so no medical problems could probably influence the test results.

\section{Results}

Statistical analysis of the data revealed that the results obtained are generally consistent to other results reported. No statistically significant differences were found according to sex. Also reliability and validity test were contacted and showed high criterion (a - Chronbach .803).

\section{Conclusions}

The test appears to be sensitive to the pre - school aged Greek population and presents satisfactory criterion, internal consistency, temporal stability, interrater reliability. Also the test showed high content validity, as the participants assessed demonstrated clear patterns of responses, but further changes must be done for the Greek version in clinical and research settings.

\section{Author details}

'Department of Speech and Language Therapy, T.E.I. of Epirus, loannina, Ioanninon, Greece. ${ }^{2}$ Department of Neural Sciences and Sensory Organs (School of medicine), University of loannina, loannina, Ioanninon, Greece. ${ }^{3}$ Department of Mathematics, National and Kapodistrian University of Athens, Athens, Attika, Greece.

Published: 22 April 2010

doi:10.1186/1744-859X-9-S1-S199

Cite this article as: Dionysios et al:: The Test of Word Finding (TWF - 2). (A pilot study and validation in Greek pre - school aged children \& data for word retrieval in this population). Annals of General Psychiatry 2010 9(Suppl 1):S199. 